\title{
The viralization of online education: Learning beyond the time of the coronavirus
}

\author{
Tatiana Stofella Sodré Rossini ${ }^{1} \cdot$ Miriam Maia do Amaral $^{1} \cdot$ Edméa Santos $^{1}$
}

Accepted: 5 February 2021 / Published online: 4 May 2021

(C) UNESCO IBE 2021

\begin{abstract}
In response to the global crisis resulted from the spread of the coronavirus in Brazil, many schools and universities suspended face-to-face classes and began to offer remote classes using digital resources. In this unprecedented crisis, educators, managers and families had to deal with unpredictability and look for new ways of learning and teaching. Based on the paradigm of transmission of mass distribution, remotely teaching has gained strength, with the teacher as the protagonist of the education process. Instead of interactivity, content is emphasized to the detriment of more participatory, dialogic, and collaborative methodologies. It is necessary to prepare teachers and students for the online education modality to face this critical moment. Thus, this article suggests online pedagogical actions supported by the multireferential research-formation and everyday school methodologies, which promote the teachers' and students' participation in an interactive and collaborative way.
\end{abstract}

Keywords Covid-19 $\cdot$ Remote education $\cdot$ Online education $\cdot$ Authorship

The pandemic caused by the new coronavirus (Covid-19) interrupts a period marked by nations' rapid and intense technological development and excessive consumerism. The earlier anticipation of significant transformations in politics, economies, and cultures has been forced because of necessary social distancing to contain the virus spread.

As far as possible, people are staying at home, transforming their habits and customs and (re)inventing their lives in the pursuit of leisure, happiness, and the pleasure of

Tatiana Stofella Sodré Rossini

tatiana.sodre@gmail.com

Miriam Maia do Amaral

amaral3378@gmail.com

Edméa Santos

edmeabaiana@gmail.com

1 Federal Rural University of Rio de Janeiro, 465 Br Road, Seropedica, Rio de Janeiro, Brasil 
coexistence and knowledge, hoping for better days. Nonessential industries, services, and commerce are paralyzed. Large and small companies have closed their doors and houses have become offices. The economy stagnates and governments try in every way to prevent the collapse of their health systems and to reduce mortality rates. Nothing is more important than saving lives and destroying the invisible Covid-19 enemy.

Indeed, Covid-19 confronts us with many complex issues related to health, death, conspiracy theories, economic recovery, job retention, and education. Because suspension of classes and changes in learning modalities concern the whole society in relation to the future of our students, it is essential to create strategies that prevent the interruption of education during this health crisis. After more than a decade of discussion about more appropriate learning and teaching methodologies, distance learning has become a viable way to continue schooling in countries.

Faced with this reality, some US multinational technology companies, such as Microsoft and Google - resurrecting concepts based on remote teaching and e-learning - offer platforms and web-based services that aim to streamline file-sharing and to manage student and teacher communications. The transition from face-to-face to online education has mostly occurred through such video chat platforms as Skype, Zoom, and Google Meet, and teachers have used these solutions in order to respect class schedules, in compliance with institutional requirements.

But the race against time by private and public universities and schools in the face of the lack of technological infrastructure and of teachers' unpreparedness for online teaching highlights the indifference of some education administrators toward the potential of digital networks. In this critical situation, many, if not most, students suffer from internet access problems, lack of computers, and lack of adequate physical space in their homes to attend web-based classes. These problems have been minimized by using asynchronous web-based resources and services (which do not need to be connected in real time) or by sending printed activities to the learners. Investment in synchronous modality has been working better in postgraduate and private schools and universities because digital inclusion is greater in those institutions. Although desirable, there is no way to guarantee online education for everyone in public institutions because of the difficulties of accessing digital networks - thus, for digital inclusion to become a reality for everyone, it is necessary that governments invest in technological infrastructure - that is, open-network connections and adequate digital equipment for students.

It is fundamental to understand the possibilities and limitations of distance education. Online education, as Silva (2003, 2018) emphasizes, cannot be understood as an evolution of conventional distance-education practices. Rather, it is an education modality that comprises, and can enhance, learning situations mediated by digital technologies in face-toface, online, or hybrid (online and face-to-face) educational modalities. Online education requires its own teaching methodology - one that profoundly changes conventional teaching models that are based on the transmission, memorization, and repetition of information and knowledge. In this scenario, it is necessary to rethink education as an emancipatory human construct that allows subjects to understand themselves as actors and authors in the cyberculture - that is, in contemporary culture mediated by digital networking-which alters modes of communication, production, sociability, and ways of learning and teaching (Santos 2019).

In this article, we propose online pedagogical actions inspired by our research conducted in an undergraduate pedagogy course at the State University of Rio de Janeiro, Brazil, from the perspective of implicit, intercommunicative, and multidimensional practices adopting shared mediation. "Shared mediation" means an interactive collaboration 
between the students and teachers; a collaboration that enables the creation of knowledge to constitute a dynamic of co-production and co-authorship. The intention of using this practice is the development of the students as authors and autonomous citizens in the construction of a less dogmatic and more unified world.

\section{Teaching through re(inventions) in cyberculture}

Conceptions and practices in the research field have been resignified by historical, social, economic, political, and technological changes. These developments have opened other modes of modern scientific understanding (which values only what is quantifiable, visible, and classifiable), establishing distinctions between scientific and non-scientific knowledge:

The scientific rigor, based on mathematical rigor, is a rigor that quantifies and, when quantifying, disqualifies; a rigor that, by objectifying phenomena, objectifies and degrades them; which, when characterizing the phenomena, caricaturize them. It is, in short, a form of rigor that, by affirming the scientist's personality, destroys the personality of nature. In these terms, knowledge gains in rigor what it loses in wealth and the resounding success of technological intervention hides the limits of our understanding of the world and represses the question of the human value of the scientific effort thus conceived. (Oliveira 2008, p. 25)

The postmodern paradigm expresses a time of ruptures. We understand the scientific or epistemological bricolage as "the ability to employ research approaches and multiple theoretical constructs" (Kincheloe and Berry 2007, p. 10). This constitutes a way of doing research in the present, within the discourse of modern science and other references from everyday life, culture, technologies, and media. This approach helps us to understand the tangle of knowledge and meanings produced in human history, and to create investigation processes for future research, bypassing the preexisting guidelines and scripts, as Kincheloe and Berry (2007) assert.

From this point of view, we base our reflections in this article on the paradigm of complexity (Morin 2014). Doing so, we adopt the following approaches: (1) research methods for everyday life-times and spaces of actions, re(inventions), experiences, and subjectivities in active participation (Andrade et al. 2019; Certeau 2018); (2) multi-referentiality, which requires the adoption of a pluralistic view regarding educational practices, facts, and phenomena from different reference systems; and (3) research-formation methodology in the context of cyberculture, which is based on scientific procedures, with a rigor founded on philosophical, epistemological and methodological bases. The researcher, in the practice-theory-practice movement, elaborates his/her interpretations with other actors, building his/her study in a relational and connective way (Santos 2019). This research methodology allows us not only to apprehend and understand the reflective, engaged, and involved practice but also to build it in a process, contributing to the formation of thinking-capable subjects who are independent and rational.

Certeau (2018) states that in everyday school life it is possible to perceive micro differences where most people see obedience and uniformity. Perceiving such differences demands that one evaluate the actions of practitioners (students and teachers), giving visibility to how they appropriate and re-signify cultural or material objects in their practices, through subtle astuteness and silent tactics. 
It is fundamental that teachers be receptive and ready to incorporate, interrogate, analyze, and try to understand everything students present to them. These spaces and times, are always crossed by events that, as Galeffi (2016, p. 13) says, do not constitute "gamesplayed, but games-playing" and lived lives; they simply happen to those who allow themselves to experience them. These "times and spaces" of knowledge and creation, full of diversity and also "of pleasure, intelligence, imagination, memory and solidarity" (Alves 1998, p. 18), enable us, through a sensitive and listening view, to better understand implicit, unexplained relations, and possible silences in the teachers' and students' relationship (Amorim 2004). They also give us an opportunity to face the uncertainties inherent in a method that is "done by doing"-in the words of Macedo (2016), a "thought adventure" that demands experience, creativity, curiosity, and implication, and invites us to immerse with all our senses, seeking references of sounds, varieties of tastes and odors, touching people and objects, and letting them touch us, for a better understanding of the complexity and connection of knowledge, powers, and actions woven into these spaces. This favors the collaborative construction of communicational practices and the process of pedagogical mediation, in both face-to-face and online teaching modalities.

In this way, bricolaging these methodological approaches allows us to understand how the students produce and reproduce what hegemonic discourses impose on them. It allows us to experience, as Santos (2019) points out, the subjects' cultural contexts and to interact with their technical objects, cultural productions, and ways of doing, interpreting, and understanding the world, which do not need scientific explanations and justifications to legitimize their practices.

As we trace and weave together the different reports that emerged in the "practice-theory-practice" movement in different spaces, we have our own ways of telling conversations and narratives (text, imagery, sound). These are mediated by the curricular practices that we created, supported by different intellectual and material resources (Alves 1998), and they open a range of possibilities as counterpoints to the single path pointed out by modern science. Exercising an "other rigor", which breaks with the Cartesian model of research, "requires countless dives, deaths and resurrections. Unauthorized hunting. Back and forth" (Ferraço 2008, p. 113). It requires courage to embark on an unknown journey with the students, experiencing chaotic movements of order and disorder in a co-authorship relation.

\section{Online education as a teaching modality on Web 2.0 platforms}

Online education emerged in cyberculture in an interactive communicational logic fostered by the development and consolidation of telematic networks and Web 2.0 platforms in people's everyday lives (Santos 2019). With the evolution of the internet from Web 1.0 (1991) to Web 2.0 (2004), users stop being passive consumers of static pages and became producers and collaborators in the construction and customization of open and dynamic services. According to Kerres (2006), the main potentials of Web 2.0 are:

- User-author: the user goes on to (re)create and modify content and express his/her opinions;

- Remote data: data are stored on remote web servers and can be accessed and reused by anyone anywhere;

- Shared files: private files are shared over the network, making them accessible to everyone; user communities maintain and dynamically create these files. 
Emerging in the Web 2.0 generation, we find: social media platforms (Facebook, Instagram); weblogs (Blogspot, Wordpress); microblogs (Twitter, Jaiku); podcasts, P2P networks (Napster, Limewire); wikis (Wikispaces); Learning Management Systems, or LMSs (Moodle); Massive Open Online Courses, or MOOCs (edX, Cursera); applications developed for mobile devices (smartphones, tablets); and video call and text messaging (WhatsApp, Skype, Google Hangouts). In these ambiences, people form virtual communities in which they expect a degree of engagement in a logic based on the exchange of information, media (e.g., photo, video, image, audio, text), and knowledge. These communities contribute to the emergence of new cultural and educational practices and of new applications, which in turn contributes to a continuum of improvement, and so on.

Online teaching modalities enable the articulation of Web 2.0 platforms in both classroom and virtual environments. Teachers need to know the resources and functions of these platforms so they can explore them according to their pedagogical objectives and intentions. Once they are familiar with these platforms, they can foster new pedagogical practices by providing guidance to a wide variety of nuanced and multidimensional educational content and situations.

In online education, teachers can structure pedagogical practices on LMS platforms developed specifically for teaching. LMS Moodle is a widely used reference environment for developing complementary collaborative activities of higher education because it is easy to manipulate its synchronous and asynchronous features. Moodle also allows teachers to organize their classes using graphic tools, without requiring technical programming knowledge.

With the intensification of social participation in Web 2.0 platforms, LMS lost its centrality, making space for social media platforms and for MOOCs (Massive Open Online Courses). Teachers have adopted social media platforms as educational spaces through closed groups or pages created specifically for this purpose. In this case, the pedagogical design is somewhat limited due to its available functionalities, since newer posts are presented before older ones, sequentially and chronologically. Teachers use most instant messaging and voice applications and services as support devices. MOOCs emerged when several international educational institutions began to offer free access to open content from undergraduate and graduate courses to the academic community.

This content, called Open Educational Resources (OER), may be digital course materials, lesson plans, videos, images, books-duly licensed (Creative Commons) for their reuse or (re)appropriation in order to safeguard the authors' intellectual property rights. In a parallel movement to open platforms, large companies such as Google and Microsoft have developed educational cloud platforms that combine video-chat resources with upload- and download-file functionalities; for these platforms, one must purchase a license to access all the resources.

However, continuous teachers' training is necessary to produce interactive pedagogical innovations in different educational modalities (face-to-face, online, and hybrid). Silva (2018) states that interactivity is the conscious and complex availability of more communication between subjects, promoting interactions mediated by the teachers in both online and face-to-face modalities. It is based on three recursive binomials: participation-intervention, bidirectionality-hybridization, and permutability-potentiality. The first one is related to teachers' and students' interactions with each other in a collective learning process. The second one concerns communication traffic (emission and reception) to establish coauthorship; the third refers to the multiplicity of materials created, shared, and remixed during the class. 
To establish interactivity, the authors (students and teachers) need an environment that provides communication and exchanges between them. For this, several digital platforms can provide a complex communication context that allows participation, collaboration, knowledge creation, and sharing between authors. Silva (2003) suggests adopting the metaphor of hypertext, in which the teacher assumes the role of a knowledge challenger, a problem maker, a proponent of situations, a path architect, a multiple and collective intelligence mobilizer. Knowledge is made available in a way that enables the learners to experience and participate in the development of their own learning. Learning exchanges can be made with both teacher-students and teacher(s)-teacher(s). These open connections foster teacher and student autonomy and favor the exchange of knowledge because nothing is static and consolidated. Knowledge is (re)constructed and (re)signified for each interaction between the participants.

Therefore, online education in Web 2.0 platforms has the potential for learning-teaching in a transformative, interactive, collaborative, and emancipating way. Thus, we need teacher training for this modality, with the aim of educators developing pedagogical ideas for online teaching.

\section{Curriculum acts in online environments}

Quarantine measures for the Covid-19 crisis came as a surprise to most public and private universities and schools; some educational institutions had no budget to acquire online educational platforms. In this scenario, teachers, without the proper preparation to work in distance education, use different strategies to carry out the official curriculum and various tactics to meet emerging demands. Tactics consist of the teachers' and students' ability to use certain inventions and ways of resistance to appropriate cultural or material consumption objects, giving them a new meaning (Certeau 2018).

In the contemporary educational setting, the official curriculum is understood as a set of knowledge and activities legitimized as formative, that reveals itself as "one of the most authoritative inventions of pedagogical history, in the face of its non-democratic conception and implementation, until today" (Macedo and Macedo 2012, p. 5). It criticizes the knowledge currently taught in schools, cities, and cyberspace because it is standardized and regulated by the hegemonic curricular policies of modern science. Such knowledge is treated as something that can be widely transferred and reproduced from methods and logics that are generalized and hierarchical and that control and exclude at the same time; however, it is crucial to understand that learning involves dynamic and dialectic processes of meaning and subjectification.

In teaching, teachers engage in certain tactics (Certeau 2018) to subvert the standardization and regulation of curricula, thus minimizing the totalitarian effects of instituted curricular policy. This requires, as Bakhtin (2011) states, active teachers, with a reflexive conscience endowed with political, social, aesthetic, and ethical purposes and values that mediate the act of teaching. Macedo (2010) points out that teachers and students need to perceive each other's contexts and cultures; in projecting and identifying with one another's feelings, motivations, and afflictions, they replace rejection and exclusion with dialogue, tolerance, and respect.

In this sense, curricular dynamics must reflect and mediate the differences and contradictions that emerge in socially constructed teaching-learning practices, in which all agents involved in the relationship are transformed into curriculum actors and authors (Macedo and Macedo 2012; Santos 2019). These "curriculum acts" allow ways of teaching and 
learning that uncover differences and ambivalences currently obscured by official policies that support a hegemonic curriculum. The experiences in teachers' and students' everyday lives are the reference points for new dialogical and dialectical learning.

Pretto (2012) argues that the teacher's work needs to be inspired by "hacker ethics", in which authorship, collaboration, sharing, exploration, creativity, and remixing are part of his/her practice. Such practice has a view to an emancipator education; it emphasizes the need for teachers to adopt a more critical and activist attitude and to be able to plan and offer a pluralist education, one that is attuned to people's differences.

Today, software developers design curricular teaching content on Web 2.0 platformsvia "the planning, production and operation of content and learning situations", as highlighted by Silva (2010, p. 219) — that take into account pedagogical, communication, and technological possibilities, as well as the interactivity provisions, inherent in online learning environments. We can observe, in this health crisis context, teachers' preference for real-time video transmission offered by such social media platforms as YouTube, Instagram, and Facebook, which allow teachers and students to livestream their discussions. They are able to record these real-time discussions and make them available on other platforms, thus configuring their own educational material. In addition, many pedagogical proposals emphasize instrumental, reactive knowledge, centered on programmatic content; and others provide opportunities for dialogue, interactivity, creativity, and collaboration, generating new possibilities for the learning process (Silva 2018).

However, most of these approaches, carried out through web conferences, reproduce the conventional paradigm in which "education continues to be, even on the online computer screen, what it has always been: bureaucratic repetition or transmission of packaged contents" (Silva 2003). Although these online meetings promote a virtual relation, providing a potentially enriching experience as they awaken in students a feeling of belonging to a group, they provide only opportunities for interactivity.

In the institutionalized LMS, we found that such didactic design is offered preformatted, and it is up to the teacher to adapt his/her practice on it. The teacher makes the content (texts, images, sounds, videos) available before class to students for discussion at online meetings, through integrated web-conferencing services such as Google Meet and Zoom. In this case, configuring new paths is not possible for teachers or students, as they must follow a standardized and static itinerary.

In other platforms, such as Moodle, the teacher can build on the platform's didactic design; that is, s/he has more flexibility to use the various available resources to enable her/his pedagogical objectives. Adding to the didactic design requires two distinct actions: "constructing information", or bringing together the content to be developed, through semantic approaches; and "constructing navigation", or establishing the relationship between the content and the hierarchy. The altered design must also contain a clear interaction proposal, with well-defined content that allows the user to easily navigate through different pages with a view to promoting communication between all participants.

Because Moodle is equipped with asynchronous (e.g., forum, glossary, wiki, diary) and synchronous (e.g., video and text chat) communication resources designed to promote interactivity among participants, and also with content resources that make it possible to produce and share digital materials in various formats and languages, it promotes decentralization of knowledge and sharing of information, configuring itself as a pedagogical and democratic environment.

However, we believe that the simple adoption of digital platforms in education does not in and of itself promote interactivity and the creation of knowledge. Students' engagement and collaboration in pedagogical activities are directly related to the structuring of learning 
and teaching and, now, to the digital resources through which knowledge is shared. The silencing of students' microphones and/or the lack of dialogue between teachers and learners simply transposes the expository model of teaching to the digital world and reduces the benefits of real-time interactions to studying on one's own. Thus, without an embedded design that enables shared learning, the functions and power offered by Web 2.0 platforms go unfulfilled.

\section{Contemporary challenges for online education after the Coronavirus pandemic}

Organizational changes, often painful and almost always generating uncertainties, demand institutional adaptation, innovation, restructuring, reframing, flexibility, and leadership. This makes us understand the crisis that we face today as an opportunity for educational (re)inventions, given that: (1) remote education solutions can help mitigate heterogeneous conditions of access, depending on the circumstances of the students, but their effect is limited in that they require national standardization and coordination; (2) the teacher is not prepared to conduct online teaching; (3) remote education or distance education is not the same as online education; and (4) learning gaps, if not remedied upon the students' return to school, may determine the future of learning.

\section{How can online education help meet contemporary challenges?}

Talking about contemporaneity and futuristic scenarios can be much more difficult than trying to interpret and describe historical trends, although we cannot disconnect these discussions. It seems necessary to accept certain losses (deaths, ends) so that we can glimpse the new and make it emerge.

Because the digital network is opened to a multiplicity of connections, it produces changes in our ways of thinking, being, and/or acting; for this reason, governments must democratize access by adopting policies that guarantee the subjects' rights So, it is more than having a modern communication infrastructure and "intelligent" digital platforms, but it is necessary that governments give subsidies to the citizens to transform information into knowledge to achieve concrete learning outcomes. However, learning will be most effective - or only effective - if it is related to our students' reality and culture. In addition to content, it is equally important that educators add value to this modality, allowing the development of dialogic, collaborative, and interactive processes between teachers and students. This construction of knowledge allows students to reflect and establish significant relationships between the contents they learn.

Despite the diversity and multiplicity of elements inherent in this process, methodologies that help students develop leadership in the learning process have been gaining prominence, either through research carried out to prove their effectiveness or in the classroom. This progress is due to adherence to these practices by teachers and higher education institutions, who have allowed a variety of arrangements to develop the autonomy and emancipation of students considered "active subjects", responsible for their own learning.

Among these methodologies, we highlight:

(1) the inverted classroom (flipped classroom), a strategy based on the concept of hybrid teaching that-supported by video lessons, blogs, games and/or audio files 
available on the network-enables the student to prepare his/her studies, making face-to-face debate more meaningful since participants are able to reflect on what has been addressed;

(2) project-based learning, which uses cross-cutting themes; students are challenged to develop a project related to their personal or professional life, one that focuses on the competencies necessary to solve such problems;

(3) problem-based learning, which calls on students to build their conceptual, procedural, and attitudinal learning through proposed problems that challenge each to individually study a particular subject and note any doubts or difficulties discussed in groups during class-in this way, problem solving stimulates different styles of student learning, reading, and logical reasoning, increases students' sense of responsibility, and develops critical thinking, teamwork skills, and information exchange; and (4) games and gamification, which are increasingly present in different fields of knowledge and levels of teaching; with its language of challenges, rewards, competition, and cooperation, games remove the student from the condition of the spectator, giving him/her the opportunity to build his/her own knowledge, while the important strategies of enchantment and encouragement result in rapid learning and derive from "real" life.

Despite the prevalence of expository classes, there is no doubt that students' co-authorship in the educational process represents an advance over more conservative practices. From our everyday experience over the last 20 years we have been able to identify some weaknesses arising from the use of these new methodologies, such as: (1) anxiety and insecurity on the part of students who are faced with a model of participatory and collaborative teaching that requires discipline, effort, maturity, organization, and autonomy to deal with online ambiences and a great quantity of materials, activities, and information; (2) the student's lack of commitment to his/her own learning, which is expressed in the absence of questions relevant to the context and reflects a lack of reading and participation in classes; (3) excess of requested tasks, depending on the time required to perform them; (4) emphasis on deepening the content to the detriment of its wider scope; (5) teachers' perception of online learning implementation failure, attributed to inappropriate support by the institutional staff; (6) teacher discomfort regarding the learning-assessment process, because their lack of physical contact with students both during the development of the work and in group activities complicates individual evaluation; and (7) restricted performance of the teacher, who is seen as a facilitator of learning, or a kind of "tutor" to simplify the acquisition of knowledge.

Candau and Moreira (2009) emphasize that educational processes should be conceived as historically situated and articulated to other social processes. Thus, in addition to the students' leadership in the learning process, it is necessary that teachers promote the integration between teaching and research in their practices. That is, they should learn at the same time as they teach and research (Santos 2019), experiencing their personal paths through a process of reflection (i.e., self-formation), in relationships with others, and through, for example, knowledge, techniques, culture, arts, technologies, and critical understanding (Pineau 1988). In the relational dynamics between these processes lies the constitutive complexity of the teacher's and student's (trans)formation.

Under this perspective, online education can help reconfigure teachers' roles in digital environments. Among other considerations, this demands the creation, throughout the educational process, of what is actually taught and learned (practiced curriculum), which considers: 
(1) the integrative dimension, through approximating different school spaces, the previous experiences of practitioners, and the ways in which they learn and construct their knowledge, in addition to considering the need for a pluralistic exploration that aligns theory and practice in a practice-theory-practice dialectic;

(2) the formative dimension, which has enabled teacher-development experiences, such as alterity, the negotiation of meanings, and the sharing of knowledge and affection; and (3) the technological dimension, which considers the transformations of traditional communication processes, sociability, education, and learning through digital networking by developing an open and flexible pedagogical design; such design involves various combinations of languages along various hypertextual pathways that allow shared mediations via dialogical, interactive, and collaborative processes.

We offer some curricula activities that teachers can use to promote collective authorship in online education:

\section{(1) Short video or comic-book production}

The students should attend an online workshop before the collaborative activity to understand the video or comic-book production processes:

(a) Pre-production: video or comic-book planning, from the initial idea to the filming or drawing itself, such as:

(i) Synopsis: general summary of the video or comic book.

(ii) Argument: brief description of how the action will be developed.

(iii) Script: division of the video scenes; theme and dialogues of characters without yet including the illustrations.

(b) Storyboard (video only): representation of the scenes in sequential drawings, as in a comic book, that facilitates visualization before the video is recorded;

(c) Production (video only): stage in which scenes are recorded;

(d) Diagramming (comic book only): comics are sketched without the dialogue, containing the characters in the script. This layout of the comics, together with the art, composes the visual narrative, which must follow, in our context, the Western reading pattern (left to right, top to bottom);

(e) Post-production or final version: final stage, defined by the editing and organization of the recorded shots (video) or the consolidation of the script and layout to be colored using image editing software.

\section{(2) Collaborative writing tool}

A collaborative writing tool must be adopted during video or comic-book production. It is the space where the students collaboratively write the artifact's synopsis, argument, and script. The students can discuss the idea, using the chat tool and together construct the activity. The teacher should follow the discussion, intervening when necessary.

The practices above underscore the intentionality of "learning by doing" through interaction with others and considering the students' prior knowledge as the basis for the creation process. In this perspective, one learns in all phases of the video or comic-book 
production with conscious, dynamic, and creative authorship. In the learning-teaching process, the production of these artifacts has enabled: (1) the development of critical thinking; (2) the promotion of expression and communication; (3) learning in a multi-referential, flexible, and practical way; and (4) the mobilization of various skills and of valuing interaction, creativity, and the feeling of co-responsibility.

In our research, collaborative activities (dialogue, interactivity, shared mediation, and negotiation of meanings) permeated the entire process of creation. The videos and the comic books produced by the students were presented to the class with the participation of all members of the group, who had the opportunity to answer some of the other students' questions. We reiterate that when the teaching-learning process is based on the principles of interactivity, it encourages subjects to become actors and authors of their daily transformation stories. Thus, it is necessary to seek solutions by which more participatory methodologies of teaching come to dominate the "transmission-of-content" model adopted in most educational institutions. These participatory models are the framework of democratic and pluralistic citizen education, focused on the creation of knowledge through shared mediation.

\section{Conclusions}

We are experiencing an overwhelming crisis of intercontinental dimensions: the coronavirus pandemic has reached an unprecedented magnitude of uncertain duration and catastrophic consequences, whether in the social, political, economic, or educational arena. Everything is new to us, not least the resulting social isolation, which has forced us to reformulate our teaching practices and ways of acting. The closure of schools is far from ideal, but it is the measure that is needed at this time. Technologies applicable to the learning-teaching process, long available to create content and learning experiences, are now resuscitated by various schools, universities, and educational networks in their search for immediate educational solutions to minimize the impacts of the pandemic.

We know that these changes have generated political, social, labor, family, and economic conflicts of all orders and magnitudes. Dissatisfaction increases every day, whether due to institutions' lack of technological infrastructure, to connectivity problems (which accentuate social exclusion), to loss of affection and jobs, to stressed parents having to help their children with their studies, or to teachers' lack of specific pedagogical foundations for creating online activities. However, a good number of educators and parents consider it unreasonable to interrupt school activities for an indefinite period; they emphasize the importance of public access for distance-learning in order to avoid increasing, even more, the existing gap between private- and public-school students. For all these reasons, the transition from teaching face to face to teaching via online platforms has been a great challenge for educators at all levels of schooling.

Despite the relevance of classroom education, the current moment invites teachers and students to experience the potential of digital networks, especially with current synchronous and asynchronous digital learning and teaching environments. However, it is necessary to remember that teaching will be the most effective the closer it is to the reality and culture of our learners. Therefore, more than asking students to simply absorb content (as with traditional expository teaching), it is necessary for teachers to take advantage of the integrative dimensions of the learning-teaching process, the experiences, and the potential of the digital network. 
In fact, it is essential to adopt more participatory methodologies in favor of democratic and pluralistic citizen education, aimed at the creation of knowledge through shared mediation. Knowledge must be gained in partnership with students, whether face to face, online, or through a hybrid modality that promotes specific engagements in which the learningteaching process is not focused on the teacher or the students, but on the relationships that these actors establish among themselves and with the primary object of learning.

\section{References}

Alves, N. (1998). Trajetórias e redes na formação de professores [Trajectories and networks in teacher education]. Rio de Janeiro, Brazil: DP\&A.

Amorim, M. (2004). O pesquisador e seu outro: Bakhtin nas ciências humanas [The researcher and his other: Bakhtin in the science in humanities]. São Paulo, Brazil: Musa Editora.

Andrade, N., Caldas, A., \& Alves, N. (2019). Os movimentos necessários às pesquisas com os cotidianos: "Após muitas conversas acerca deles" [The movements necessary for everyday life research: "After many conversations about them"]. In I. B. Oliveira, L. Peixoto, \& M. Süssekind (Eds.), Estudos do cotidiano, currículo e formação docente: Questões metodológicas, políticas e epistemológicas [Daily studies, curriculum and teacher formation: Methodological, political and epistemological issues] (pp. 19-45). Curitiba, Brazil: CRV.

Bakhtin, M. (2011). Estética da criação verbal [Aesthetics of verbal creation]. São Paulo: Martins Fontes.

Candau, V., \& Moreira, A. F. (2009). Educação escolar e cultura(s): Multiculturalismo, universalismo e currículo [School education and culture(s): Multiculturalism, universalism and curriculum]. In V. Candau (Ed.), Didática: Questões contemporâneas (pp. 47-62). Rio de Janeiro: Forma \& Ação.

Certeau, M. (2018). A invenção do cotidiano: Artes de fazer [The invention of everyday life: Arts of making] (22nd ed.). Rio de Janeiro: Vozes.

Ferraço, C. (2008). Ensaio de uma metodologia efêmera ou sobre as várias maneiras de sentir e inventar o cotidiano escolar [Essay on an ephemeral methodology or on the various ways of feeling and inventing the school routine] (pp. 101-17). In I. B. Oliveira \& N. Alves (Eds.), Pesquisa nos/dos/com os cotidianos das escolas [Research in/with the daily lives of schools]. Petrópolis, Brazil: DP et Alii.

Galeffi, D. A. (2016). Prefácio [Preface]. In R. Macedo (Ed.), A pesquisa e o acontecimento: Compreender situações, experiências e saberes acontecimentais [Research and the event: Understanding situations, experiences and event knowledge] (pp. 13-19). Salvador, Brazil: EDUFBA.

Kerres, M. (2006). Potenziale von Web 2.0 nutzen [Use the potential of Web 2.0]. In Handbuch e-Learning (vol. 17, pp. 1-16). Munich: DWD. http://learninglab.uni-due/sites/default/files/web20-a.pdf.

Kincheloe, J. L., \& Berry, K. S. (2007). Pesquisa em educação: Conceituando a bricolagem [Education research: Conceptualizing bricolage]. Porto Alegre: Artmed.

Macedo, R. (2016). A pesquisa e o acontecimento: Compreender situações, experiências e saberes acontecimentais [The research and the event: Understanding situations, experiences and event knowledge]. Salvador, Brazil: EDUFBA.

Macedo, R. (2010). Compreender/mediar a formação: O fundante da educação [Understanding / mediating formation: The foundation of education]. Brasília: Liber Livro.

Macedo, R., \& Macedo, S. M. (2012). Currículo: Implicações conceituais [Curriculum: Conceptual implications]. In A. Ramal \& E. Santos (Eds.), Currículos: Teorias e práticas [Curriculum: Theories and practices] (pp. 3-17). Rio de Janeiro: LTC.

Morin, E. (2014). A cabeça bem-feita: Repensar a reforma, reformar o pensamento [A well-made head: Rethinking reform, reforming thinking] (15th ed.). Rio de Janeiro: Bertrand Brasil.

Oliveira, I. B. (2008). Boaventura \& a Educação [Boaventura and the Education] (2nd ed.). Belo Horizonte: BrazilAutêntica.

Pineau, G. (1988). A autoformação no decurso da vida: Entre hetero e a ecoformação [Self-formation in the course of life: Between hetero and ecoformation]. In A. Nóvoa \& M. Finger (Eds.), O método (auto) biográfico e a formação [The (auto) biographical method and formation] (pp. 65-77). Lisbon: Ministério da Saúde, http://forumeja.org.br/files/autopineau.pdf.

Pretto, N. (2012). Networked teacher-authors. In B. Santana, C. Rossini, \& N. Pretto (Eds.), Recursos educacionais abertos: Práticas colaborativas políticas públicas [Open educational resources: Public policy collaborative practices] (pp. 91-108). Salvador, Brazil: EDUFBA; São Paulo: Casa da Cultura Digital. https://www.aberta.org.br/livrorea/livro/livroREA-1edicao-mai2012.pdf. 
Santos, E. (2019). Pesquisa-formação na cibercultura [Formation-research in cyberculture]. Teresina, Brazil: Brazil EDUFPI.

Silva, M. (2018). Sala de aula interativa: educação, comunicação, mídia clássica [Interactive classroom: Education, communication, classic media]. São Paulo: Edições Loyola.

Silva, M. (2010). Desenho didático: Contribuições para a pesquisa sobre formação de professores para a docência online [Didactic design: Contributions to research on teacher formation for online education]. In M. Silva, L. Pesce, \& A. Zuin (Eds.), Educação online: Cenário, formação e questões didáticometodológicas [Online education: Scenario, training and didactic-methodological issues] (pp. 215-31). Rio de Janeiro: Wak Ed.

Silva, M. (2003). Educação online: Teorias, práticas, legislação e formação corporativa [Online education: theories, practices, legislation and corporate formation]. São Paulo: Loyola.

Publisher's Note Springer Nature remains neutral with regard to jurisdictional claims in published maps and institutional affiliations.

Tatiana Stofella Sodré Rossini holds a doctoral degree in education from the State University of Rio de Janeiro (2015) and a master's degree in education from Estácio de Sá University (2011). She specialized in systems engineering at Estácio de Sá University (1998) and graduated in data processing from Estácio de Sá University (1996). She is currently a researcher at the Teaching and Cyberculture Research Group at the Federal Rural University of Rio de Janeiro and an IT consultant at Caixa Econômica Federal bank.

Mirian Maia do Amaral holds a PhD and a master's in education from Estácio de Sá University, with a concentration in information and communication technology. She did her postdoctoral work in education at the State University of Rio de Janeiro. Formerly a specialist in human resources and administration at Fundação Getulio Vargas, she graduated with a degree in literature from the State University of Guanabara and in pedagogy from Sociedade Augusto Motta University. She is currently a researcher at the Teaching and Cyberculture Research Group at the Federal Rural University of Rio de Janeiro.

Edméa Santos (Brasil) is a professor at the Federal Rural University of Rio de Janeiro. She works at the Institute of Education and in the Graduate Program in Education, on "Contemporary Studies and Educational Practices". She was an associate professor at the Faculty of Education of the State University of Rio de Janeiro (PROPED / UERJ) from 2007 to 2018 (where she contributed on the area "Daily Life, Educational Networks and Cultural Processes"). She is the chief editor of the magazine Teaching and Cyberculture and holds a master's and a $\mathrm{PhD}$ in education from the Federal University of Bahia. She has done postdoctoral work in e-learning and distance learning at the Open University of Portugal and is a leader of the Teaching and Cyberculture Research Group at the Federal Rural University of Rio de Janeiro. 